\title{
PENERAPAN PENDIDIKAN KARAKTER DALAM MENINGKATKAN PROGRAM PEMBELAJARAN PEMBERDAYAAN MASYARAKAT
}

\author{
Muhammad Sulistiono, Afifatu Nur Arifah, Ahmad Musyadad Al Arifi, Angga \\ Chidlomul Adzim, Devi Alifna Anggraeni, Dewy Nur Fitriana, Ella Amalia Hadi, Ervina \\ Rahma Dwi Andriyani, Ilham Ali Yafie, Lintang Dewi Kusumaningrum, Luluk Azizah \\ Fakultas Agama Islam, Universitas Islam Malang
}

Korespondensi email: muhammad.sulistiono@unisma.ac.id

\begin{abstract}
ABSTRAK
Desa Ketawang Kecamatan Gondanglegi merupakan sebuah desa yang terletak di salah satu Kabupaten yang terletak di Provinsi Jawa Timur yaitu Kabupaten Malang. Desa ini secara geografis berada di Kabupaten Malang bagian selatan, yang mana untuk bagian selatan berbatasan dengan Desa Putat Lor, bagian utara berbatasan dengan Desa Putukrejo, bagian barat berbatasan dengan Desa Ganjar dan bagian timur berbatasan dengan Desa Urek-urek. Karena Desa ini terletak di bagian Malang Selatan yakni termasuk salah satu akses atau jalan utama menuju pantai selatan sehingga biasanya terjadi kepadatan lalu lintas ketika hari libur. Universitas sebagai penyelanggara Tri-Dharma Perguruan Tinggi khususnya Kuliah Kerja Nyata (KKN) bersinergi dalam membangun daerah. Dengan adanya program KKN-PPM ini maka secara signifikan akan mendorong masyarakat melalui pendidikan. Dengan metode partisipatif yang mana sasaran dari Pelaksanaan KKN-PPM adalah masyarakat Desa Ketawang. Dalam melaksanakan kegiatan KKN PPM, peserta KKN PPM 2020 berpartisipasi dalam bidang pendidikan karakter, kebudayaan berbasis kearifan lokal dan administrasi desa. Dimana dalam bidang pendidikan peserta terjun ke sekolah setempat, kegiatan pendidikan lain serta dengan diadakannya lomba anak, guna mewadahi potensi aanka serta mengembangkan kretivitas anak. Termasuk dalam bidang administrasi desa peserta berperan aktif dalam kegiatan kantor desa, serta kegiatan masyarakat sekitar.
\end{abstract}

Kata Kunci: pendidikan; karakter; kearifan lokal.

\section{PENDAHULUAN}

Desa Ketawang Kecamatan Gondanglegi Kabupaten Malang merupakan salah satu tempat yang dipilih dan ditunjuk Universitas Islam Malang untuk menjadi tempat pelaksanaan KKN-PPM di tahun 2020 ini. Kegiatan pengabdian di desa Ketawang dibimbing satu dosen dan 28 orang mahasiswa yang tergabung dalam kelompok reguler B, yakni kelas PAI reguler B angkatan 2016.

Desa Ketawang Kecamatan Gondanglegi merupakan sebuah desa yang terletak di salah satu Kabupaten yang terletak di Provinsi Jawa Timur yaitu Kabupaten Malang. Desa ini secara geografis berada di Kabupaten Malang bagian selatan, yang mana untuk bagian selatan berbatasan dengan Desa Putat Lor, bagian utara berbatasan dengan Desa Putukrejo, bagian barat berbatasan dengan Desa Ganjar dan bagian timur berbatasan dengan Desa Urek-urek. Karena Desa ini terletak di bagian Malang Selatan yakni termasuk salah satu akses atau jalan utama menuju pantai selatan sehingga biasanya terjadi kepadatan lalu lintas ketika hari libur. 
Berdasarkan hasil pengamatan yang dilakukan tim KKN-PPM Kelompok Reguler B di Desa Ketawang memiliki masyarakat yang heterogen, sehingga dalam penyusunan suatu program musyawarah dalam mencapai mufakat menjadi mutlak menyesuaikan tradisi, kondisi, situasi, dan potensi yang dimiliki oleh Desa Ketawang.

Adapun target yang dicapai dalam kegiatan KKN-PPM tahun 2020 adalah Manfaat bagi masyarakat:

1. Penerapan ilmu pengetahuan serta Pemanfaatan Teknologi Informasi dalam berbagai aktivitas terlebih dalam pengembangan profil desa.

2. Memberdayakan masyarakat melalui training dan workshop untuk belajar ke-aswajaan guna menjadikan warga yang agamis.

3. Dapat melatih dan membatu masyarakat Ketawang dalam mengembangkan pengetahuan dengan melalui safari dakwah ketika kegiatan dasawisma dan PKK.

Lustia (2016) mendefinisikan Pendidikan secara etimologi berasa dari bahasa Yunani yang terdiri dari kata "Pais" artinya seseorang, dan "again" diterjemahkan membimbing. Jadi pendidikan (paedogogie) artinya bimbingan yang diberikan pada seseorang. Sedangkan secara umum pendidikan merupakan bimbingan secara sadar oleh pendidik terhadap perkembangan jasmani dan rohani peserta didik menuju terbentuknya kepribadian yang utama. Kepribadian yang membawa pada kesadaran penuh yang tendesius pada kebaikan (Kurniasih et al., 2019).

Pendidikan dipandang sebagai salah satu aspek yang memiliki peranan pokok dalam membentuk generasi muda agar memiliki kepribadian yang utama (Arifin \& Tamrin, 2019). Dan di dalam Islam, sekurang-kurangnya terdapat tiga istilah yang digunakan untuk menandai konsep pendidikan, yaitu tarbiyah, ta`lim, dan ta`dib. Namun istilah yang sekarang berkembang di dunia Arab adalah tarbiyah (Khoiri, 2019).

Istilah tarbiyah berakar pada tiga kata, raba yarbu yang berarti bertambah dan tumbuh, yang kedua rabiya yarba yang berarti tumbuh dan berkembang, yang ketiga rabba yarubbu yang berarti memperbaiki, menguasai, memimpin, menjaga, dan memelihara. Kata al rabb juga berasal dari kata tarbiyah dan berarti mengantarkan pada sesuatu kesempurnaannya secara bertahap atau membuat sesuatu menjadi sempurna secara berangsur-angsur (Syah, 2008) (Hasan et al., 2020).

Jadi definisi pendidikan secara harfiah bermakna membimbing, memperbaiki, menguasai, memimpin, menjaga, dan memelihara. Subtansi dari pendidikan adalah adanya proses transfer nilai, pengetahuan, dan keterampilan dari generasi tua kepada generasi muda agar generasi muda mampu hidup (Nurkholis, 2013) (Martino et al., 2018). Oleh karena itu, ketika kita menyebut pendidikan agama Islam, maka akan mencakup dua hal, yaitu:

1. Mendidik peserta didik agar berperilaku sesuai dengan nilai-nilai dan akhlak Islam dalam kehidupan sehari-hari.

2. Mendidik peserta didik agar mempelajari dan memahami materi ajaran agama Islam sesuai jenjang pendidikan.

Sedangkan pengertian pendidikan jika ditinjau secara definitif telah diartikan atau dikemukakan oleh para ahli dalam rumusan yang beraneka ragam, diantaranya adalah:

1. Kamrani Buseri (2014) mendefinisikan bahwa pendidikan Islam sebagai sebuah sistem yang terefleksi dalam berbagai bentuk kelembagaan pendidikan seperti madrasah, pesantren dan perguruan tinggi telah memperlihatkan sesuatu kesungguhan, karena selain telah memiliki program yang jelas juga telah mendapatkan apresiasi dari masyarakat. 
Pendidikan yang terinstitusikan ke dalam sistem tertentu sesuai dengan pola dan karakteristik yang dimiliki. Seperti pondok pesantren dipimpin oleh seorang Kiyai, Ustad adalah pendidik, santri adalah murid atau peserta didik

2. Hakim (2015) pendidikan agama Islam adalah suatu usaha untuk membina dan mengasuh peserta didik agar senantiasa dapat memahami ajaran Islam secara menyeluruh. Lalu menghayati tujuan, yang pada akhirnya dapat mengamalkan serta menjadikan Islam sebagai pandangan hidup.

Definisi ini tidak terbatas pada formal dan informal, sekalipun di dalam lingkungan masyarakat sekalipun. Pendidikan agama Islam tetap menjadi cara untuk memahami ajaran Islam.

Dengan demikian berdasarkan keterangan-keterangan sebelumnya Pendidikan Agama Islam adalah perubahan sikap dan tingkah laku sesuai dengan petunjuk ajaran agama Islam dalam rangka pembentukan karakter manusia seutuhnya (Ainiyah, 2013).

Dari beberapa definisi di atas dapat diambil unsur yang merupakan karakteristik Pendidikan Agama Islam:

1. Pendidikan Agama Islam merupakan bimbingan secara sadar yang diberikan oleh pendidik terhadap peserta didik di dalam forum formal maupun informal.

2. Keberlanjutan dalam proses bimbingan menjadi multak karena proses ini dilakukan sesuai dengan perkembangan kematangan peserta didik.

3. Dalam pelaksanaan pemberian bimbingan tidak terlepas dari pengawasan sebagai proses evaluasi.

\section{METODE}

Program yang dijalankan oleh tim pengabdi berlandaskan pada filsafat postpositivisme yang digunakan untuk pengamatan pada kondisi obyek yang alamiah (Sugiyono, 2015). Dengan pengamatan lapangan pengabdi terjun dan terlibat langsung dalam kelompok masyarakat atau lingkungan, sehingga informasi yang didapatkan lebih akurat. Kegiatan ini dilaksanakan di Desa Ketawang Kecamatan Gondanglegi Kabupaten Malang pada tanggal 31 Januari s.d. 29 Februari 2020.

\section{HASIL DAN PEMBAHASAN}

Tim pengabdi merencanakan beberapa program dalam meningkatkan pelaksalanaan pendidikan dan pembelajaran di Desa Ketawang Kecamatan Gondanglegi. Tim pengabdi yang mayoritas mahasiswa dengan mudah menyelesaikan dan melaksanakan semua program yang telah direncanakan. Adapun program-program yang telah dilaksanakan oleh tim sebagai berikut:

\section{Pendampingan Taman Pendidikan Al-Qur'an (TPQ)}

Tabel 1. Program kerja pendampingan Taman Pendidikan Al-Qur'an (TPQ)

\begin{tabular}{ll}
\hline \multicolumn{1}{c}{ Deskripsi Kegiatan } & \multicolumn{1}{c}{ Keterangan } \\
\hline Tujuan & 1. Membimbing anak-anak membaca Al-Qur'an. \\
& 2. Membantu anak-anak dalam memahami tata cara sholat. \\
Manfaat & Menambah khazanah ilmu agama islam. \\
Tempat - Waktu & 1. TPQ Assa'diyah - Ba'da Magrib \\
& 2. TPQ Ar-Rohmah - Ba'da Ashar \\
& 3. TPQ Bpk. Kasturi - Ba'da Ashar \\
& 4. TPQ Bu. Sumiati - Ba'da Dhuhur \\
Anakaran & 1. TPQ Assa'diyah - 18 \\
Jumlah peserta & 2. TPQ Ar-Rohmah - 30 \\
& 3. TPQ Bpk. Kasturi - 20
\end{tabular}




$\begin{array}{ll} & \text { 4. TPQ Bu. Sumiati - } 20 \\ \text { Sambutan Masyarakat } & \text { Antusias } \\ \text { Hambatan } & \text { 1.Kurangnya kesadaran masyarakat akan pentingnya mengaji } \\ & \text { 2.TPQ sepi ketika turun hujan karena banyak murid yang tidak } \\ & \text { masuk } \\ \text { Hasil yang dicapai } & \text { Tim KKN-PPM Kelompok reguler B mengajarkan cara membaca } \\ & \text { Al-Qur'an yang benar sesuai tajwid, mengajarkan tata cara } \\ & \text { bersuci dan sholat. }\end{array}$

Dengan terjun langsung ke lokasi TPQ, para peserta KKN PPM Unisma 2020 dapat menyalurkan ilmu yang telah lama didapat. Dengan pemberlakuan program pendampingan TPQ, peserta KKN PPM juga menyelipkan pendidikan karakterkepada para murid.

Dengan sikap sikap yang diterapkan oleh peserta langsung terhadap murid memberikan gambaran beradab terhadap guru, orang tua dan teman sebaya. Seperti halnya yang dilakukan para peserta KKN PPM ketika datang ke TPQ bertemu dengan guru mencium tangan lantas mengucap salam.

Pendidikan karakter yang diterapkan pula pada orang tua ditunjukkan oleh peserta dengan bersikap sopan santun pada wali murid yang menunggui putra putrinya mengaji. Disamping itu, pendidikan karakter yang dituju pada teman sebaya ditunjukkan dengan berbicara dengan lembut, tidak kasar serta tidak bercanda secara berlebihan.

Hal ini terapkan oleh peserta KKN PPM untuk memberikan contoh secara langsung bagaimana seharusnya ia bersikap terhadap guru, orang tua maupun teman sebaya. Dengan anak-anak belajar al-qur'an di TPQ dapat menunjang potensi dmembaca al-qur'an baik itu dari hal yang dasar sampai yang tinggi. Sekalipun hanya membaca al-qur'an, murid TPQ juga dituntun untuk dapat qiro'ah, yakni membaca alqur'an dengan nada yang indah didengar maupun kefashihan pelalafalan dan kelancaran membaca al-qur'an. Dari potensi qiro'ah ini, dapat mencetak generasi qur'ani yang dapat menunjang kearifan local, yangmana "basic" nya Desa Ketawang juga merupakan desa pesantren.

\section{Pendampingan Madrasah Ibtidaiyah (MI)}

Tabel 2. Program kerja pendampingan Madrasah Ibtidaiyah (MI)

\begin{tabular}{|c|c|}
\hline Deskripsi Kegiatan & Keterangan \\
\hline Tujuan & $\begin{array}{l}\text { Membantu anak-anak dalam memahami tata cara thoharoh dan } \\
\text { sholat. }\end{array}$ \\
\hline Manfaat & $\begin{array}{l}\text { Menambah khazanah ilmu agama islam khususnya dalam } \\
\text { pembahasan thoharoh dan sholat. }\end{array}$ \\
\hline Tempat - Waktu & $\begin{array}{l}\text { 1. MI Miftahul Huda - Pukul } 10.00 \text { s.d } 12.00 \\
\text { 2. MI Ihyaussalafiyah - Pukul } 10.00 \text { s.d } 12.00\end{array}$ \\
\hline Sasaran & Siswa kelas IV, V, dan VI \\
\hline Jumlah peserta & $\begin{array}{l}\text { 1. MI Miftahul Huda - } 80 \text { siswa } \\
\text { 2. MI Ihyaussalafiyah - } 46 \text { siswa }\end{array}$ \\
\hline Sambutan Masyarakat & Antusias \\
\hline Hambatan & $\begin{array}{l}\text { 1. MI Miftahul Huda : Kenakalan siswa } \\
\text { 2. MI Ihyaussalafiyah : Jauhnya lokasi sekolah, }\end{array}$ \\
\hline Hasil yang dicapai & $\begin{array}{l}\text { Tim KKN-PPM Kelompok reguler B mengajarkan tata cara } \\
\text { bersuci dan sholat. }\end{array}$ \\
\hline
\end{tabular}


Program pendampingan MI ini bertujuan untuk membantu pihak yang bersangkutan, baik dari isntansi maupun komposisi instansi tersebut. Dalam pendampingan MI, para peserta KKN PPM UNISMA 2020 tidak lupa untuk memberikan pengabdiannya dalam bentuk menemani belajar murid MI, hingga memberikan konseling bagi murid yang terkait.

Dengan latar belakang murid yang beragam peserta KKN PPM UNISMA 2020 mencoba untuk dapat menyesuaikan dengan murid. Pendidikan karakter yang telah dikantongi diajarkan, di "wejang" kan pada murid guna murid memiliki karakter yang baik.

Bersalam ketika berjumpa guru, mencium tangan, hingga berkata halus diterapkan oleh peserta KKN PPM untuk memberikan gambaran langsung pada murid. Berkaitan dengan kearifan local daerah yang lebih maju dalam bidang budaya seperti pesona Gondanglegi yakni pawai kesenian yang setiap tahunnya digelar, murid juga dididik untuk selalu melesetarikan daerah sekitar serta mengembangkan kreatifitas dan imajinasi bagi murid yang memiliki hobi dalam bidang seni.

\section{Kegiatan Dasawisma}

Tabel 3. Program kerja kegiatan Dasawisma

\begin{tabular}{|c|c|}
\hline Deskripsi Kegiatan & Keterangan \\
\hline Tujuan & Bersosialisasi dengan ibu-ibu Desa Ketawang \\
\hline Manfaat & $\begin{array}{l}\text { 1.Dapat memahami karakteristik penduduk Desa Ketawang } \\
\text { 2.Menambah khazanah ilmu }\end{array}$ \\
\hline Tempat - Waktu & Rumah warga - Pukul. 14.00 \\
\hline Sasaran & Ibu-ibu anggota Dasawisma \\
\hline Jumlah peserta & 40 \\
\hline Sambutan Masyarakat & Antusias \\
\hline Hambatan & $\begin{array}{l}\text { 1.Tidak semua ibu-ibu sekitar mengikuti kegiatan dasawisma } \\
\text { 2.Kegiatan Dasawisma di dominasi oleh ibu-ibu yang sudah tua } \\
\text { 3.Kurangnya partisipasi oleh pemudi sekitar }\end{array}$ \\
\hline Hasil yang dicapai & $\begin{array}{l}\text { 1.Diterimanya para mahasiswi yang mengikuti kegiatan } \\
\text { dasawisma } \\
\text { 2.Bertukar ilmu dan pengalaman antara mahasiswi dengan } \\
\text { anggota dasawisma }\end{array}$ \\
\hline
\end{tabular}

Para ibu Desa Ketawang juga memiliki waktu tersendiri untuk melaksanakn pertemuan. Dimana dalam pertemuan ini para ibu membahas tentang bagaimana desa yang mereka tempati bias maju dan memiliki ikon tersendiri. Dalam kegiatan dasawisma ini para ibu berpartisipasi untuk memajukan desa, dengan membuat produk produk buatan daerah local, seperti halnya mi lidi sapu jagad, rangakaian bunga plastik, hingga minuman local seperti jahe instan.

Produk produk tersebut kemudian didistribusikan di BUMDES milik desa, yang terletak sebelah Kantor Desa Ketawang yang diberi nama "TawangGros". Dengan memperkerjakan warga sekitar BUMDES yang tak lama dibuka menjadi salah satu ikon DEsa Ketawang.

Program yang dilaksanakan peserta KKN PPM UNISMA 2020 dalam partisipasi dasawisam ini bertujuan untuk selain mengetahui potensi para warga dan juga desam juga memberikan contoh perilaku halus pada ibu ibu. Seperti juga yang dilakukan oleh peserta KKN PPM UNISMA 2020 memberikan "ijazah" atau disebut juga wirid, doa untuk ibu hamil, serta safari dakwah atau ceramah keagamaan yang dititik beratkan pada poin akhlaq. 


\section{Rutinan Tahlil Warga}

Tabel 4. Program kerja pembacaan tahlil bersama warga

\begin{tabular}{ll}
\hline \multicolumn{1}{c}{ Deskripsi Kegiatan } & \multicolumn{1}{c}{ Keterangan } \\
\hline Tujuan & Bersosialisasi dengan Bapak-Bapak Warga Desa Ketawang \\
Manfaat & $\begin{array}{l}\text { 1.Dapat memahami karakteristik penduduk Desa Ketawang } \\
\text { 2.Menambah khazanah ilmu }\end{array}$ \\
Tempat - Waktu & Rumah warga Desa Ketawang \\
Sasaran & RW.03 dan RW. 04 Warga Desa Ketawang \\
Jumlah peserta & 50 \\
Sambutan Masyarakat & Antusias \\
Hasil yang dicapai & 1.Diterimanya para mahasiswa yang mengikuti kegiatan tahlil \\
& rutin setiap malam jum'at \\
& 2.Bertukar ilmu dan pengalaman antara mahasiswa dengan \\
& jama'ah tahlil RW.03 dan RW.04 Desa Ketawang \\
\hline
\end{tabular}

Perkumpulan yang dilakukan oleh para bapak Desa Ketawang dalam menjaga adat yang telah mendarah daging, serta menjaga kelangsungan hidup salah satunyan dengan adanya tahlil. Dimana perkumpulan tahlil ini bertujuan untuk mendoakan seseorang, juga menambah khazanah ilmu.

Peserta KKN PPM UNISMA 2020 memberlakukan program ini, bertujuan untuk dapat berbaur dengan masyarakat, namun juga untuk menyelipkan karakter baik secara langsung. Seperti halnya peserta KKN PPM UNISMA 2020 mendahulukan yang lebih tua disbanding dirinya, meskipun peserta mampu melakukan tetap mendahulukan yang lebih senior. Dalam artian peserta KKN PPM UNISMA 2020 menyiratkan menghormati satu sama lain dan yang lebih tua.

\section{Pengajian Aswaja}

Tabel 5. Program kerja pengajian Aswaja

\begin{tabular}{ll}
\hline \multicolumn{1}{c}{ Deskripsi Kegiatan } & \multicolumn{1}{c}{ Keterangan } \\
\hline Tujuan & Berbaur dengan masyarakat sekitar melalui pengajian aswaja \\
Manfaat & 1.Menambah khazanah ilmu tentang kitab aswaja \\
& 2.Mempererat rasa kekeluargaan dengan warga sekitar \\
Tempat - Waktu & Kantor Aswaja Ketawang - Sabtu pukul 19.00 \\
Sasaran & Masyarakat sekitar \\
Jumlah peserta & 80-90 \\
Sambutan Masyarakat & Antusias \\
Hasil yang dicapai & 1.Pengetahuan tentang aswaja \\
& 2.Turut berkontribusi mensukseskan kegiatan rutin pengajian \\
& aswaja \\
& 3. Diterimanya para mahasiswa yang mengikuti kegiatan aswaja \\
& rutin setiap malam ahad \\
\hline
\end{tabular}

Peserta KKN PPM UNISMA 2020, ikut berpartisipasi pula dalam satu ajaran yang tak jauh dari lingkup dimana ia menimba ilmu, yakni pengajian aswaja. Dengan pengajian aswaja ini, warga memberlakukan adat yang telah senantiasa terjaga, yakni "Desa Ketawang beriman". Dimana para warga meskipun memiki pekerjaan bagaimanapun tidak lupa untuk kembali dan mengingat tuhanya. Selain itu peserta KKN PPM UNISMA 2020, memeberikan semangat pada para warga, untu senantiasa belajar, meskipun sudah berumur. 


\section{Lomba Antar TPQ}

Tabel 6. Program kerja lomba antar TPQ

\begin{tabular}{ll}
\hline \multicolumn{1}{c}{ Deskripsi Kegiatan } & \multicolumn{1}{c}{ Keterangan } \\
\hline Tujuan & Mengasah skill para santri TPQ \\
Manfaat & 1. Mengetahui skill para santri TPQ \\
& 2. Mengembangkan potensi, kretifitas anak \\
& 3. Mempererat rasa silaturahmi \\
Tempat - Waktu & Kantor Desa Ketawang - Sabtu tgl 29 Februari 2020 pukul \\
& 13.30 \\
Sasaran & Santri TPQ \\
Jumlah peserta & 50 \\
Sambutan Masyarakat & Antusias \\
Hambatan & Cuaca tidak bersahabat ( hujan ) \\
\hline
\end{tabular}

Lomba yang diselenggarakan olleh peserta KKN PPM UNISMA 2020, ini bertujuan untuk mengasah potensi, kepercayaan diri da kreatifitas anak. Dengan diadakannya lomba ini, kontribusinya anak yang memiliki bakat dapat terkuak potensinya.

Dengan demikian, "Desa Ketawang Beriman" lebih maju dengan anak yang memiliki potensi qiro'ah, tartil, dan adzan. Lebih lagi dari lomba mewarnai sendiri kontribusinya dapat menunjukkan pada khalayak bahwa anak tersebut berpotensi dalam bidang seni yang kedepannya dapat melesetarikan bahkan berpartisipasi dalam "pesona Gondanglegi" , dimana kedua hal tersebut merupakan beberapa kearifan local daerah setempat. Perlombaan yang berjalan lancar, serta pembudayaan antri dan ramah anak, merupakan tindakan langsung sebagai bentuk pendidikan karakter bagi anak.

\section{KESIMPULAN}

Adapun kesimpulan dalam laporan ini adalah kegiatan KKN-PPM Unisma dengan sasaran masyarakat Desa Ketawang berjalan dengan lancar sesuai dengan apa yang direncanakan walaupun ada beberapa kegiatan yang tidak sesuai dengan rundown. Perubahan dan tambahan serta waktu pelaksanaan terjadi karena mempertimbangkan kondisi musim hujan pada bulan ini. Secara keseluruhan program ini dapat berjalan dengan baik berkat dukungan dan kerjasama antar seluruh Tim KKN-PPM, pihak desa, dan pihak masyarakat yang sangat membantu dan mendukung. Dengan demikian kesimpulan menjelaskan bahwa secara global program KKN-PPM berjalan sukses dan lancar.

Pelaksanaan program KKN-PPM yang dilaksanakan sejak 03 Februari 2020 sampai tgl 29 Februari 2020, terdapat beberapa saran yang konstruktif bagi semua pihak antara lain:

\section{Bagi Masyarakat Desa Ketawang}

a. Partisipasi warga untuk mengikuti berbagai kegiatan kemasyarakatan harus ditingkatkan, dalam rangka menjawab tantangan global, karena setiap kegiatan yang diselenggarakan memiliki tujuan memberi manfaat dan kebaikan bagi warga sekitar secaya khusus dan masyarakat secara umum.

b. Kedisplinan dalam menghadiri kegiatan diharapkan dapat lebih tepat waktu.

2. Bagi Kepala Desa Ketawang

a. Program-program yang telah dilaksanakan oleh Tim KKN-PPM hendaknya ada tindak lanjut untuk peningkatan selanjutnya. 
b. Hubungan yang telah terjalin antara pihak universitas dengan pihak masyarakat hendaknya lebih ditingkatkan dan dapat memberikan umpan balik satu sama lain.

\section{DAFTAR RUJUKAN}

Ainiyah, N. (2013). Pembentukan Karakter Melalui Pendidikan Agama Islam. Al-Ulum: Jurnal Studi Islam, 13(1), 25-38.

Arifin, Z., \& Tamrin, T. (2019). Peningkatan Kompetensi Microcontroller Siswa SMK. Jurnal Inovasi Hasil Pengabdian Masyarakat (JIPEMAS), 2(1), 49-53. https://doi.org/10.33474/jipemas.v2i1.1772

Hakim, A. R. (2015). Metode Pengajaran Pendidikan Agama Islam Di Perguruan Tinggi. AlMabsut: Jurnal Studi Islam Dan Sosial, 9(2), 259-267. https://ejournal.iaingawi.ac.id/index.php/almabsut/article/view/97

Hasan, N., Setyowidodo, G., Wafa, M. S., Irfan, M., Riadi, S., Annafisah, K., Alfanny, M. I. R., Aprilia, I., Faizin, T. G., Rizkiyah, N., \& Qowim, A. N. M. (2020). Pemberdayaan santri melalui pembelajaran enjoyable learning dalam membentuk generasi seimbang dan spiritualitas intelektualitas di pondok pesantren. Jurnal Pembelajaran $\begin{array}{lll}\text { Pemberdayaan } \quad \text { Masyarakat } & \text { (JP2M), }\end{array}$ https://doi.org/10.33474/jp2m.v1i2.6582

Khoiri, A. (2019). Upaya Kepala Sekolah dan Guru Pendidikan Agama Islam Dalam Mencegah Penyalahgunaan Narkoba di SMA PAB 4 Sampali Deli Serdang. Jurnal Ansiru PAI, 3(1), 73-86. http://repositorio.unan.edu.ni/2986/1/5624.pdf

Kurniasih, Rahmati, N. A., Umamah, A., \& Widowati, D. R. (2019). English Conversation Class (ECC) Untuk Menciptakan English Environment Di SMA Islam Nusantara (SMAINUS). Jurnal Inovasi Hasil Pengabdian Masyarakat (JIPEMAS), 2(2), 161-169. https://doi.org/10.33474/jipemas.v2i2.2571

Lustia, L., Noer, F., \& Devi, R. (2016). Trend Pemakaian Hijab Ibu-ibu di Pusat Perbelanjaan Kota Banda Aceh. Jurnal Ilmiah Mahasiswa Pendidikan Kesejahteraan Keluarga 1.1, 1(1), 93-101.

Martino, Y. A., Sulistiowati, E., \& Purnomo, Y. (2018). Model Pemberdayaan Santri Ponpes Al-Hidayah Batu Alang Sebagai Kader Kesehatan Berbasis Terapi Herbal. Jurnal Inovasi Hasil Pengabdian Masyarakat (JIPEMAS), 1(2), 86-93. https://doi.org/10.33474/jipemas.v1i2.1514

Nurkholis. (2013). Pendidikan Dalam Upaya Memajukan Teknologi. Jurnal Kependidikan, 1(1), 24-44. https://doi.org/10.24090/jk.v1i1.530

Prof. Dr. H. Kamrani Buseri, M. (2014). Dasar, Asas dan Prinsip Pendidikan Islam.

Sugiyono. (2015). Metode Penelitian Kuantitatif, Kualitatif dan Kombinasi (1st ed.). Alfabeta.

Syah, A. (2008). Term Tarbiyah, Ta'lim dan Ta'dib dalam Pendidikan Islam: Tinjauan dari Aspek Semantik. Al-Fikra: Jurnal Ilmiah Keislaman, 7(1), 138-150. https://doi.org/10.24014/af.v7i1.3786 